\title{
Progression of non-cavitated lesions in dentin through a nonsurgical approach: a preliminary 12-month clinical observation
}

\author{
Ana Daniela Silva da Silveira ${ }^{1}$ \\ Boniek Castillo Dutra Borges ${ }^{1}$ \\ Hugo de Almeida Varela' \\ Kenio Costa de Lima1 \\ Isauremi Vieira de Assunção Pinheiro'
}

\begin{abstract}
Objective: Considering the minimally invasive approach to dentistry, the scientific community has focused on non-invasive treatments for caries lesions. The aim of this study was to evaluate the efficacy of a nonsurgical approach to arrest occlusal non-cavitated dentin lesions through glass ionomer sealing.
\end{abstract}

Methods: In this controlled clinical trial, 51 teeth with clinically non-cavitated occlusal caries radiographically located beneath the enamel-dentine junction (radiolucent area) were selected among patients presenting a moderate to high risk of caries. The teeth were randomly divided into two groups: an experimental group receiving an application of Vidrion-R (SS White) glass ionomer and a control group not submitted to any clinical intervention. Caries progression was monitored by clinical and radiographic examination at 4-monthly intervals over a period of one year. In addition, marginal integrity of the sealant was evaluated in the experimental group.

Results: Clinical examination showed no statistical difference between the groups $(P=.13)$. On the other hand, sealed teeth presented lower caries progression when analyzed by radiographic examination $(P=.004)$.

Conclusion: A glass ionomer sealant over non-cavitated occlusal caries lesions in dentin may not be sufficiently effective in arresting their progression. (Eur J Dent 2012;6:34-42)

Keywords: Pit and fissure sealant; glass ionomer cement; dentin; caries; clinical trial.

1 Department of Dentistry, Federal University of Rio Grande do Norte, Natal, RN, Brazil.

- Corresponding author: Dr. Boniek Castillo Dutra Borges Department of Dentistry, Federal University of Rio Grande do Norte Av. Senador Salgado Filho 1787, Natal, RN, Brazil Zip-code: 59.056-000

Phone/fax: +55 8432154101

E-mail: boniek.castillodgmail.com

\section{INTRODUCTION}

In recent years, the minimally invasive dentistry approach to treatment of caries lesions has developed, with the trend towards the maximum possible preservation of dental tissues. ${ }^{1}$ Nonsurgical procedures without using burs are based on scientific investigation and are apparently much welcomed by patients. $^{2}$ 
The literature recognizes the possibility of arresting enamel caries progression through noninvasive preventive measures, and conservative treatment has been recommended for carious lesions affecting this dental tissue. ${ }^{3}$ Sealing caries lesions with a pit and fissure sealant ${ }^{4}$ or a glass ionomer sealant $(\mathrm{GIC}),{ }^{5}$ in addition to regular use of fluoridated dentifrice during oral health care ${ }^{6,7}$ are the main nonsurgical strategies used to treat early enamel caries.

Most dentists continue to use an invasive approach to treat occlusal lesions involving carious dentin, even when they are non-cavitated, because of the belief that it is not possible for these lesions to be remineralized or arrested. 8,9 However, MertzFairhurst et $\mathrm{al}^{10}$ and Alves et al, ${ }^{11}$ after a 10 -year follow-up, showed that the progression of cavitated occlusal dentin caries can be arrested by sealing the cavity with an adhesive material, even without the removal of any infected tissue. Moreover, Borges et al ${ }^{12}$ recently demonstrated that sealing the enamel over a non-cavitated dentin caries lesion using a resin-based sealant arrested its progression. Thus, results of these investigations point towards the possibility of effectively treating dentin caries through nonsurgical approaches.

Clinically non-cavitated caries has a thin, apparently intact enamel surface, ${ }^{13}$ so that antibacterial substances contained in saliva, such fluoride ions $^{14-16}$ are able to diffuse with the possibility of interfering in bacterial growth. In the absence of a significant number of microorganisms, caries does not progress. ${ }^{17}$ Thus it is important to evaluate the efficacy of GIC sealant on arresting non-cavitated occlusal dentin lesions, since GIC is capable of forming chemical bonds with dental substrates in addition to releasing fluoride. ${ }^{18,19}$ Fluoride released from GIC is responsible for inhibiting the acid production of caries-related oral streptococci. ${ }^{20}$ Moreover, even after macroscopic loss of GIC, a physical barrier is maintained on the fissures, ${ }^{21,22}$ which could prevent the passage of nutrients and release fluoride ions to bacteria under the enamel, making them non viable to continue dentin demineralization.

Self-polymerizing GIC has been widely used in public health programs due to being low cost and capable of high fluoride release. ${ }^{23}$ The benefits of an effective treatment of non-cavitated lesions involving dentin by means of GIC sealing, without us- ing drills, would make it possible to preserve dental tissues, in the same way as is done in enamel, with a low cost procedure. In view of these points, the aim of this study was to test the hypothesis in vivo that the nonsurgical treatment of non-cavitated occlusal dentin caries lesions, using a GIC sealant would be effective in arresting them.

\section{MATERIALS AND METHODS}

Ethical Considerations

The project was approved by the Research Ethics Committee of the local institution. All patients or their parents/guardians received information about the study and signed a free informed term of consent in accordance with Resolution 196/6 of the National Health Council and the Declaration of Helsinki (2000).

\section{Experimental Design}

This randomized and controlled clinical trial followed the CONSORT statement. ${ }^{24}$ Teeth were randomly divided into two groups: an experimental group submitted to treatment with a glass ionomer sealant and educational intervention; and a control group that received only educational intervention. Dependent variables studied were the presence or absence of clinical and radiographic caries progression. Independent variables included age (years), gender (male/female), tooth position in the arch (maxillary/mandibular), and occlusion (contact with antagonist tooth/infraocclusion).

\section{Study Population}

All procedures were conducted in a town (Natal, $\mathrm{RN}$, Brazil) where there is no public water supply fluoridation, and the sample was selected among patients presenting a moderate to high risk of caries laccording to the Thompson and Kaim ${ }^{25}$ criteria) who sought a public health (Federal University of Rio Grande do Norte) service for dental care.

The sample consisted of 38 volunteers, who had not used any antibiotics during the period of 2 months prior to the study, whose teeth were examined and 51 permanent molars were selected for inclusion in the study. Inclusion criteria were (1) teeth presenting non-cavitated caries lesions by visual examination and (2) caries depth between the enamel-dentine junction and middle one-third of dentine in radiograph. Exclusion criteria were the presence of restorations and white spot le- 
sions or cavitations on other tooth surfaces. Teeth presenting reported sensitivity to any type of stimulus were also excluded.

Both the visual and radiographic exams were performed by a single trained and calibrated operator. Visual examination was made after pumice and water prophylaxis, using a flat mirror (SSWhite, Rio de Janeiro, RJ, Brazil), triplex syringe and headlight (Gnatus, Araraquara, SP, Brazil). For radiographic examination, bite-wing radiography was performed using a positioner (Indusbello, Londrina, PR, Brazil) to visualize the carious lesion depth.

A random sampling method was used, in which a number was assigned to each eligible tooth and then put into a sealed opaque envelope. The envelopes were randomly selected by an examiner who allocated the teeth to each group of this investigation.

\section{Clinical Steps}

All teeth selected for the study were again submitted to clinical and radiographic examination. After prophylaxis with pumice and water, clinical examination was performed with a flat mirror (SSWhite, Rio de Janeiro, RJ, Brazil), triplex syringe and headlight (Gnatus, Araraquara, SP, Brazil) to confirm the absence of clinically visible cavitation on the occlusal surface. For radiographic examination, silicone biting registers were obtained and bite-wing radiography was performed using a positioner (Indusbello, Londrina, PR, Brasil) to visualize the carious lesion depth at baseline. The positioner was attached to a silicon occlusal register for each patient, since it is possible that all subsequent radiographs can be executed with the film positioned exactly in the same direction, avoiding bias. Kodak E-Speed films (Eastman Kodak Co., New York, USA, lot number 3107662) were used and radiographs were taken using the same mobile X-ray source (Timex $70 \mathrm{C}$ mobile column, Gnatus; exposure time: $0.64 \mathrm{~s}$ ). The radiographs were processed manually in Kodak developing (lot number 0637 C6 02687) and fixing (lot number 0714 B6 02251) solutions using the following temperature/time combination: $2 \mathrm{~min}$ in the developer and $4 \mathrm{~min}$ in the fixer at a temperature of $26^{\circ} \mathrm{C}$.

Next, the patients received educational intervention (instructions with regard to oral hygiene), including the Fones' technique ${ }^{26}$ for daily tooth brushing and the use of dental floss after meals. The fluoride sources used by the patients were also recorded. All procedures were performed by a single professional.

\section{Clinical Steps (Experimental Group)}

After complete rubber dam isolation (Madeitex, São José dos Campos, SP, Brazil), the tooth to be sealed was submitted to pumice and water prophylaxis with a Robinson brush (Microdont, São Paulo, SP, Brazil). Afterwards, conventional glass ionomer cement (Vidrion R, SSWhite, Juiz de Fora, MG, Brazil) was used as pit and fissure sealant. The glass ionomer cement was prepared according to manufacturer's instructions. The material was inserted with a dental explorer (SS White, Rio de Janeiro, RJ, Brazil) and adjusted on the occlusal surface in such a way that it remained restricted to the sulcus, thus preventing overflow and wear and tear due to occlusion and mastication. The sealant was protected with a light polymerized adhesive (Scotchbond, Multipurpose Plus, $3 \mathrm{M}$ ESPE, St Paul, MN, USA) to prevent syneresis and imbibition.

Sealant coverage was then evaluated by visual inspection using a dental explorer (SSWhite, Rio de Janeiro, RJ, Brazil) in order to detect any pit or fissure region not covered with the resin material. Occlusal contacts were examined using carbon paper (Accu Film II, Parkell, NY, USA) to eliminate possible premature contacts. A single trained and experienced operator performed all sealing procedures of the study in accordance with the recommendations of the glass ionomer cement manufacturer.

\section{Examiner Calibration}

Before the study began, one examiner was calibrated to compare the radiolucent area detected on radiographs obtained at baseline and at the end of the study. For this purpose, 52 baseline radiographs and 52 one-year radiographs were used, which had been obtained after one year for the experimental and control groups, as part of a previous study. ${ }^{12}$ The radiographs were paired, coded and evaluated blindly by the examiner using a negatoscope, a $\times 2$ magnifying glass (Maped do Brasil, São Paulo, SP, Brazil) and a millimeter ruler (Prisma, São Paulo, SP, Brazil) in a dark room. The examiner's clerical assistant recorded 
the occurrence of an increase or decrease, or no change in the radiolucent area locclusoapical and/or mesiodistal direction in $\mathrm{mm}$ ) between radiographs positioned on the left and right side. After 15 days, $39.1 \%$ of the radiographs were reevaluated to determine intra-examiner agreement. A kappa coefficient of 0.9 was obtained, demonstrating good agreement.

\section{Observation Periods}

The experimental and control groups were followed-up at 4-monthly intervals over a period of one year to permit intervention in case of carious lesion progression. A single experienced and calibrated examiner performed the follow-up exams. During each control visit, the patient was submitted to anamnesis and repeats clinical and radiographic examination, and was asked about the presence of sensitivity to any type of stimuli, as well as about the fluoride sources used during the period preceding the visit. Clinical examination consisted of evaluating the presence of visible cavitation and marginal integrity of the sealant (only in the experimental group) using the following criterion commonly applied in the literature:27,28 total retention, partial retention and total loss. At the end of the observation period, clinical progression was defined when the teeth presented visible cavitation and/or sensitivity during this period. As regards radiographic examination, a single, previously calibrated examiner compared the dimensions of the radiolucent area (in $\mathrm{mm}$ ) at baseline with those obtained in the other observation periods.

With respect to the integrity of the sealing material, in the case of partial loss uncovered pits/ fissures received a new application of the glass ionomer sealant according to the protocol described above. In the case of total loss, new sealant was applied to the entire occlusal surface. If any sign of caries progression were perceived Itooth sensitivity, occurrence of visible cavitation or increase in the radiolucent area seen by radiograph) in either group, the tooth would be restored using phosphoric acid (Scotchbond Etchant), an adhesive system (Scotchbond, Multipurpose Plus) and a composite resin (Z250) (Table 1), according to the manufacturer's recommendations. A LED curing unit (Ultra-Blue IS, DMC, São Carlos, SP, Brazil) at an intensity of $600 \mathrm{~mW} /$ $\mathrm{cm}^{2}$ was used to light polymerize both adhesive and composite.
Analysis of the Radiographs

Baseline radiographs and those obtained after one year were compared again to confirm the progression of caries during this period. A single calibrated and blinded examiner performed this exam with a negatoscope and a x2 magnifying glass in a dark room, and identified cases of progression and arrest of carious lesions in the groups studied. Cases in which the final radiograph showed an increase in any of the analyzed directions (occlusoapical and mesiodistal) were defined as caries progression. Carious process arrest was defined in two situations: no change or a reduction in one or both dimensional planes after one year.

\section{Statistical Analysis}

To determine the homogeneity of the sample the groups were first compared in terms of gender, location of the tooth in the dental arch and the presence of caries in neighboring and antagonist teeth (chi-square test), stage of eruption and degree of occlusion (Fisher's exact test), and age (Student's-t test for independent samples). With respect to the dependent variables, the control and experimental groups were compared in terms of the progression or arrest of the carious lesions detected by clinical (presence of cavitation and/ or tooth sensitivityl and radiographic examination (increase of the radiolucent area). The clinical progression of caries was compared between the two groups by the chi-square test, whereas Fisher's exact test was used for comparison of the increase in the radiolucent area on bitewing radiographs. Moreover, in the experimental group the association between the number of glass ionomer cement replacements on the occlusal surfaces and the clinical and radiographic progression of caries was evaluated using the chi-square test. GraphPad InStat Demo software for windows was used to perform all the statistical tests.

\section{RESULTS}

All the teeth examined at baseline could be evaluated after 1-year follow-up. Characteristics of the sample lquantitative and categorical variables) and homogeneity of the groups regarding independent variables are shown in Table 2. Comparison showed that the groups were similar in terms of baseline characteristics ( $P>05$ ).

Only fluoridated toothpaste was used as a source of fluoride by the patients of two groups 
during follow-up period: Tandy Morango (Colgate, São Paulo, SP, Brazil) and Tandy Uva (Colgate, São Paulo, SP, Brazil), both containing 1100 ppm fluoride. All patients used exogenous fluoride.

With respect to glass ionomer cement retention, total retention was observed in all the teeth $(100 \%)$ at 4 months. After 8 months, total retention was observed in 16 teeth (19.16\%) and total loss in $11(40.74 \%)$. Five (18.51\%) teeth, in which complete loss of sealant had already been noted and replacement had been made at the last observation time, presented total loss again after 1-year of follow-up. Thus, $11(40.74 \%)$ teeth had no sealant replacement (no sealant loss), 11 (40.74\%) had one sealant replacement and 5 (18.52\%) had two sealant replacements.

Clinical and/or radiograph caries progression was observed in the teeth allocated to the control group after eight months, whereas in the experimental Group, it was perceived after one year. Analysis of clinical caries progression showed no association between group and the condition of the tooth at the end of the study $(P=.13)$ (Table 3$)$. There was

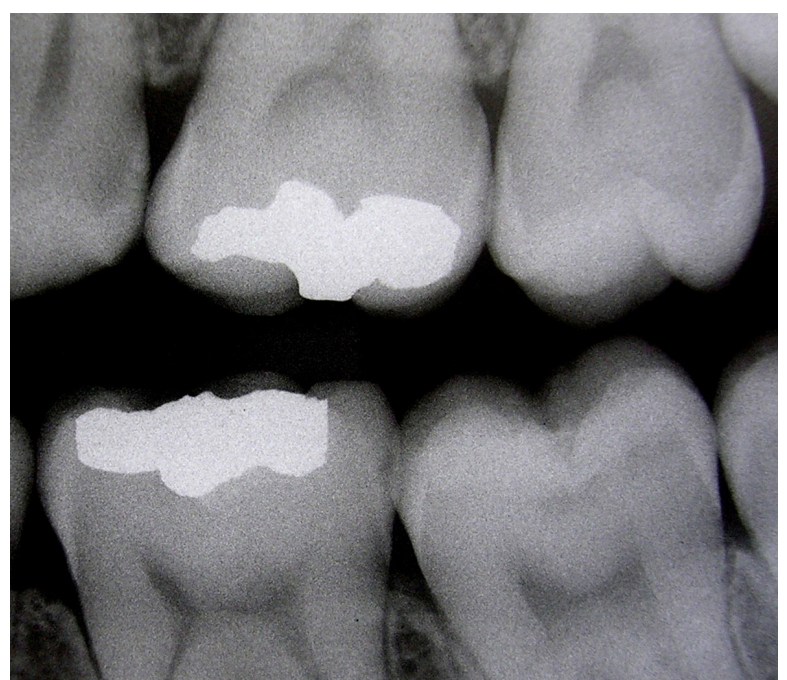

Figure 1. Radiographic aspect of tooth 37, corresponding to a specimen of the experimental group at baseline.

Table 1. Materials used in this study.

\begin{tabular}{lccc}
\hline Material/manufacturer & Classification & Composition & Lot \\
\hline $\begin{array}{l}\text { Vidrion R - SS White, Rio de Janeiro, RJ, } \\
\text { Brazil }\end{array}$ & Conventional glass ionomer & $\begin{array}{c}\text { ANa-Ca-Al-flurosilicate-Ba } \\
\text { sulfate, acrylic acid }{ }^{\text {} T a r t a r i c ~ a c i d, ~} \\
\text { water }\end{array}$ & 131207 100907 \\
$\begin{array}{l}\text { Scotchbond Etchant - 3M ESPE, St Paul, } \\
\text { MN, USA }\end{array}$ & - & Phosphoric acid (35\%) & 7JL \\
$\begin{array}{l}\text { Adper Scotchbond Multi Purpose - 3M } \\
\text { ESPE, St Paul, MN, USA }\end{array}$ & Etch-and-rinse adhesive & 'Water, HEMA, acid copolymers; \\
$\begin{array}{l}\text { Filtek Z250, A2 shade - 3M ESPE, St Paul, } \\
\text { MN, USA }\end{array}$ & Microhybrid composite & $\begin{array}{c}\text { Silane treated ceramic, Bis-EMA, } \\
\text { UDMA, Bis-GMA, TEGDMA }\end{array}$ & 7BK 7PY \\
\hline
\end{tabular}

Apowder, ${ }^{B}$ liquid, ${ }^{C}$ primer, ${ }^{D}$ bond a $56 \%$ decrease in the relative risk of clinical caries progression occurring among the sealed teeth.

Radiograph evaluation of caries progression showed a significantly higher prevalence in the teeth of the control group $(P=.004)$ (Table 4). There was a $78 \%$ decrease in the relative risk of radiological caries progression occurring among the sealed teeth (Figures 1 and 2).

Age, gender, tooth position, caries in neighboring and antagonist teeth, stage of eruption, degree of occlusion and number of sealant replacements (experimental group) (Table 5) were not significantly associated with clinical and radiographic caries lesion progression ( $\mathrm{P}>$.05).

\section{DISCUSSION}

The hypothesis tested in the present investigation was partially accepted. GIC sealant was capable of arresting non-cavitated occlusal dentin caries only shown in radiographic examination. However, clinical examination showed that the sealed teeth presented caries progression similar to those that were not sealed.

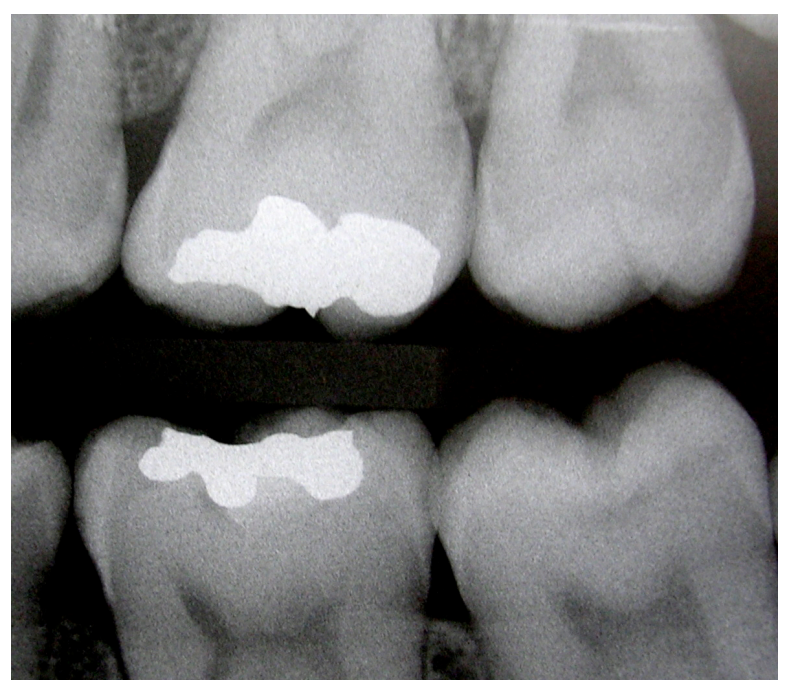

Figure 2. Radiographic aspect of tooth 37 after one year, which showed no caries progression. 
When a low viscosity GIC is placed over pit and fissure sealants, remnants of the material can be found in the bottom of fissures even following macroscopic sealant loss, ${ }^{21}$ which allows continuous fluoride release into the deep fissure enamel. Fluoride has antibacterial activity, ${ }^{29}$ so that inhibition of bacterial metabolism possibly occurred and demineralization was arrested in this study, as observed by radiographic examination.

Other authors have shown that long-term fluoride release from glass-ionomers can occur for periods lasting from several months to over three years. ${ }^{30}$ However, in cases of clinical loss of GIC from the teeth included in this study, the remnants of material at the bottom of the fissure may not seal it properly, allowing diffusion of thermal stimuli that cause dentinal hypersensitivity. In addition, the superficial surfaces of fissures were exposed to oral conditions after macroscopic loss of GIC, which may have favored the growth of microorganisms responsible for the caries progression process, leading to the appearance of enamel cavitations, as observed by clinical analysis in this investigation.

With regard to total retention of self-polymerizing GIC and fissure sealants, low levels have been reported for GIC, ranging between $5.8 \%$ and $10.5 \%,{ }^{23,31}$ being in agreement with the results of the present investigation (19.16\%). The low retention levels of self-polymerizing GIC sealants can be justified due to their low mechanical strength. ${ }^{32,33}$ This fact leads to a fast loss of self-polymerizing

Table 2. Comparison of of homogeneity between experimental (Exp) e control (Cont) groups in terms of quantitative and categorical variables.

\begin{tabular}{|c|c|c|c|}
\hline Variable & Exp & Cont & $\mathrm{p}$ \\
\hline Age (years) & 13,04 & 12,53 & 0,302 \\
\hline \multicolumn{4}{|l|}{ Gender } \\
\hline Male & $20(69 \%)$ & $9(31 \%)$ & \multirow{2}{*}{0,265} \\
\hline Female & $7(46,7 \%)$ & $8(53,3 \%)$ & \\
\hline \multicolumn{4}{|l|}{ Tooth position } \\
\hline Maxillary & $10(58,8 \%)$ & $7(41,2 \%)$ & \multirow{2}{*}{0,862} \\
\hline Mandibular & $23(52,3 \%)$ & $21(47,7 \%)$ & \\
\hline \multicolumn{4}{|c|}{$\begin{array}{l}\text { Caries in neighboring teeth and } \\
\text { antagonists }\end{array}$} \\
\hline No & $23(54,8 \%)$ & $19(45,2 \%)$ & \multirow{2}{*}{0,877} \\
\hline Yes & $10(52,6 \%)$ & $9(47,4 \%)$ & \\
\hline \multicolumn{4}{|l|}{ Stage of eruption } \\
\hline Completly erupted & $32(53,3 \%)$ & $28(46,7 \%)$ & \multirow{2}{*}{1} \\
\hline Partially erupted & $1(100 \%)$ & $0(0 \%)$ & \\
\hline \multicolumn{4}{|l|}{ Degree of oclusion } \\
\hline Occluded & $28(52,8 \%)$ & $25(47,2 \%)$ & \multirow{2}{*}{0,715} \\
\hline Infraoccluion & $5(62,5 \%)$ & $3(37,5 \%)$ & \\
\hline
\end{tabular}

Values are reported as the media for age and as absolute $(n)$ and relative $[\%]$ frequency for the other variables

Table 3. Absolute and relative frequency, relative risk (RR) and confidence interval (CI) of clinical caries progression at the end of the study period.

\begin{tabular}{|c|c|c|c|c|c|}
\hline \multicolumn{6}{|c|}{ Result of clinical examination and anamnesis } \\
\hline & No clinical alterations & Sensitivity/cavitation & & & \\
\hline Group & $\mathrm{n}(\%)$ & $n(\%)$ & $\mathrm{p}$ & $\mathrm{RR}$ & $\mathrm{Cl}(95 \%)$ \\
\hline Experimental & $22(81.48)$ & $5(18.52)$ & 01 & 0 & 12 \\
\hline Control & $14(58.3)$ & $10(41.7)$ & 0,1 & 0,44 & $0.18-1.12$ \\
\hline
\end{tabular}

Table 4. Absolute and relative frequency, relative risk (RR) and confidence interval (CI) of radiographic caries progression at the end of the study period.

\begin{tabular}{|c|c|c|c|c|c|}
\hline \multirow{3}{*}{ Group } & \multicolumn{2}{|c|}{ Increase in radiolucent area } & \multirow[b]{3}{*}{$\mathrm{p}$} & \multirow[b]{3}{*}{ RR } & \multirow[b]{3}{*}{ Cl (95\%) } \\
\hline & No & Yes & & & \\
\hline & $\mathrm{n}(\%)$ & n (\%) & & & \\
\hline Experimental & 24 (88.9) & $3(11.1)$ & \multirow{2}{*}{0,004} & \multirow{2}{*}{0,22} & \multirow{2}{*}{$0.07-0.69$} \\
\hline Control & $12(50)$ & $12(50)$ & & & \\
\hline
\end{tabular}


GIC under oral conditions, as well as making retention dependant mainly on fissure morphology and the chemical composition of enamel. ${ }^{23}$ Nevertheless, although a fast loss of GIC occurred in this study, retention was not statistically associated with caries progression by clinical or radiograph evaluation criteria. Possibly, remnants of material were maintained at the bottom of the fissure after its macroscopic loss, and fluoride could progressively be released to the enamel and underlying dentine. Moreover, the use of fluoride dentifrices may have favored fluoride recharge of the GIC sealant, as shown in vitro by Cildir and Sandali. ${ }^{34}$

Although retention was not statistically associated with caries progression in this study, no clinical and/or radiographic signs were observed in teeth that did not lose their sealant. On the other hand, signs of progression were detected when sealant was lost. This finding may confirm the presupposition that lack of protection of the superficial fissure surface after macroscopic sealant loss influenced clinical caries progression. Probably, a larger sample would denote statistical association between retention and clinical progression of lesions.

In contrast to the control group, the results obtained in this investigation for experimental group demonstrated that remnants of GIC possibly present in the bottom of the fissure after its macroscopic loss could have a cariostatic effect on underlying dentine, as observed by radiographic examination. High fluoride content recharged by fluoride dentifrices and released in the bottom of the fissure was a finding of great importance in these results.

Lo, Chu and $\operatorname{Lin}^{35}$ showed that cavitated occlusal dentin lesions could be arrested by regular topical fluoride (solution or varnish) application without posterior filling of the cavity. In view of this fact, the cariostatic effect of fluoride released from dentifrices was investigated in this study with regard to non-cavitated lesions, since diffusion of this ion through enamel to underlying dentin could occur, thereby arresting the caries process. Nevertheless, the results obtained in the present study could reject this presumption, given that all the teeth analyzed were exposed to the fluoride content of dentifrices but only the sealed teeth had caries progress arrested.

Considering the minimal intervention dentistry approach, the invasive strategy must be avoided whenever possible, since any surgical treatment can begin a long sequence of re-restorations, often leading to the placement of crowns and implants, irrespective of how well the first filling was prepared. ${ }^{36}$ Therefore, the data shown in the present study has a great impact on the development of non-surgical approaches for the treatment of non-cavitated occlusal caries lesions involving dentin. Moreover, when pointing out the abovementioned results obtained by Borges et al, ${ }^{12}$ one can presume that sealing enamel on non-cavitated occlusal dentin caries lesions with a resin-based sealant is more effective in arresting this type of caries lesion, than the use of a self-polymerizing glass ionomer sealant. Resin-based dental materials provide higher bond strength to enamel than self-polymerizing GIC. ${ }^{37,38}$ Consequently, all fissure surfaces can be protected for a longer time.

\section{REFERENCES}

1- Bader JD, Shugars DA. The evidence supporting alternative management strategies for early occlusal caries and suspected occlusal dentinal caries. J Evid Base Dent Pract 2006;6:91-100.

2- Baysan A, Beighton D. Assessment of the ozone-mediated killing of bacteria in infected dentine associated with noncavitated occlusal carious lesions. Car Res 2007;41:337341.

3- Maltz M, De Oliveira EF, Fontanella V, Bianchi R. A clinical, microbiologic, and radiographic study of deep caries lesions after incomplete caries removal. Quintessence Int 2002;33:151-159.

4- Gomez SS, Basili CP, Emilson CG. A 2-year clinical evaluation of sealed noncavitated approximal posterior carious lesions in adolescents. Clin Oral Investig 2005;9:239-243.

5- Yamamoto K, Arai K, Fukazama K, Fukui K, Nagamatsu K, Kato K, Nakagaki H, Robinson C. Effect of plaque fluoride released from a glass-ionomer cement on enamel remineralization in situ. Caries Res 2005;39:157-160.

6- Zhang YP, Blake-Haskins J, Din CS, Gaffar A. The improved remineralization and fluoride uptake in vivo of triclosan/ copolymer/sodium fluoride toothpaste vs. sodium fluoride toothpaste. J Clin Dent 2003;14:23-28.

7- García-Godoy F, Hicks J. Maintaining the integrity of the enamel surface. The role of dental biofilm, saliva and preventive in enamel demineralization and remineralization. $J$ Am Dent Assoc 2008;139:25S-34S. 
8- Doméjean-Orliaquet S, Tubert-Jeannin S, Riordan PJ, Espelid I, Tveit AB. French dentists' restorative treatment decisions. Oral Health Prev Dent 2004;2:125-131.

9- Traebert J, Wesoloski Cl, Lacerda JT, Marcenes W. Threshold of restorative decision in dental caries treatment among dentists from small Brazilian cities. Oral Health Prev Dent 2007;5:131-135.

10- Mertz-Fairhurst EJ, Curtis Jr. JW, Ergle JW, Rueggeberg FA, Adair SM. Ultraconservative and cariostatic sealed restorations: results at year 10. J Am Dent Assoc 1998;129:5566.

11- Alves LS, Fontanella V, Damo AC, Ferreira de Oliveira E, Maltz M. Qualitative and quantitative radiographic assessment of sealed carious dentin: a 10-year prospective study. Oral Surg Oral Med Oral Pathol Oral Radiol Endod 2010;109:135-141.

12- Borges BCD, Campos GBP, Silveira ADS, Lima KC, Pinheiro IVA. Efficacy of a pit and fissure sealant in arresting dentin non-cavitated caries: A 1-year follow-up randomized single-blind controlled clinical trial. Am J Dent; 2010;23:311316.

13- Featherstone JDB. Dental caries: a dynamic disease process. Aust Dent J 2008;53:286-291.

14- Bibby BG, van Kesteren M. The effect of fluorine on mouth bacteria. J Dent Res 1940;19:391-402.

15- Marquis RE, Clock SA, Mota-Meira M. Fluoride and organic weak acids as modulators of microbial physiology (review). FEMS Microbiol Rev 2003;26:493-510.

16- Sheng J, Marquis RE. Enhanced acid resistance of oral streptococci at lethal $\mathrm{pH}$ values associated with acid-tolerant catabolism and with ATP synthase activity. FEMS Microbiol Lett 2006;262:93-98.

17- Balakrishnan M, Simmonds RS e Tagg JR. Dental caries is a preventable infectious disease. Aust Dent $J$ 2000;45:235245.

18- Uysal T, Amasyali M, Koyuturk AE, Sagdic D. Efficiency of amorphous calcium phosphate-containing orthodontic composite and resin modified glass ionomer cement on demineralization evaluated by a new laser fluorescence device. Eur J Dent 2009;3:127-134

19-Algera TJ, Kleverlaan CJ, Prahl-Andersen B, Feilzer AJ. The influence of environmental conditions on the material properties of setting glass-ionomer cements. Dent Mater 2006;22:852-856.

20- Nakajo K, Imazato S, Takahashi Y, Kiba W, Ebisu S, Takahashi N. Fluoride released from glass-ionomer cement is responsible to inhibit the acid production of caries-related oral streptococci. Dent Mater 2009;25:703-708.
21 - Torppa-Saarinen E, Seppä L. Short-term retention of glassionomer fissure sealants. Proc Finn Dent Soc 1990;86:8388.

22- Antenson SA, Wanuck J, Antonson DE. Surface protection for newly erupting first molars. Compend Contin Educ Dent 2006;27:46-52.

23- Vieira ALF, Zanella NLM, Bresciani E, Barata TJE, Silva SMB, Machado MAAM, Navarro MFL. Evaluation of glass ionomer sealants placed according to the ART approach in a community with high caries experience: 1-year follow-up. J Appl Oral Sci 2006;14:270-275.

24- Needleman I, Wothington $H$, Moher D, Schulz K, Altman DG. Improving the completeness and transparency of reports of randomized trials in oral health: The CONSORT Statement. Am J Dent 2008;21: 7-12.

25- Thompson VP, Kaim JM. Nonsurgical treatment of incipient and hidden caries. Dent Clin N Am 2005;49:905-921.

26- Fones $\mathrm{CA}$. Mouth hygiene. A text book for dental hygienists. Second ed. Philadelphia and New York: Lea \& Febiger 1921 ; p. 334.

27- Mascarenhas AK, Nazar H, Al-Mutuawaa S, Soparkar P. Effectiveness of pimer and bond in sealant retention and caries prevention. Pediatr Dent 2008;30:25-28.

28- Tianviwat S, Chongsuvivatwong V, Sirisakulveroj B. LosS of sealant retention and subsequent caries development. Community Dent Health 2008;5:216-220.

29- Sidhu SK, Schmalz G. The biocompatibility of glass-ionomer cement materials. A status report for the American Journal of Dentistry. Am J Dent 2001;14:387-396.

30- Wiegand A, Buchalla W, Attin T. Review on fluoride-releasing restorative materials - fluoride release and uptake characteristics, antibacterial activity and influence on caries formation. Dent Mater 2007;23:343-362.

31- Poulsen S, Beiruti N, Sadat N. A comparison of retention and the effect on caries of fissure sealing with a glassionomer and a resin-based sealant. Community Dent Oral Epidemiol 2001;29:298-301.

32- Yip HK, Smales RJ. Glass ionomer cements used as fissure sealants with the atraumatic restorative treatment (ART) approach: review of literature. Int Dent J 2002;52:67-70.

33- Choi K, Oshida Y, Platt JA, Cochran MA, Matis BA, Yi K. Microtensile bond strength of glass ionomer cements to artificially created carious dentin. Oper Dent 2006;31:590-597.

34- Cildir SK, Sandalli N. Fluoride release/uptake of glassionomer cements and polyacid-modified composite resins. Dent Mater J 2005;24:92-97.

35- Lo ECM, Chu CH, Lin HC. A community-based caries control program for pre-school children using topical fluorides: 18-months results. J Dent Res 2001;80:2071-2074. 
36- ten Cate JM. Remineralization of deep enamel dentine caries lesions. Aust Dent J 2008;53:281-285.

37- Alonso RC, Correr GM, Borges AF, Kantovitz KR, Rontani RM. Minimally invasive dentistry: bond strength of different sealant and filling materials to enamel. Oral Health Prev Dent 2005;3:87-95.

38- Papacchini F, Goracci C, Sadek FT, Monticelli F, GarcíaGodoy F, Ferrari M. Microtensile bond strength to ground enamel by glass-ionomers, resin modified glass-ionomers, and resin composites used as pit and fissure sealants. $J$ Dent 2005;33:459-467. 